\title{
Comparison of Coronary Bypass Grafting Surgery with Carotid Endarterectomy and Coronary Bypass Grafting Surgery
}

\author{
Aykut Sahin, Cengiz Ovali \\ Cardiovascular Surgery Department, Faculty of Medicine, Eskisehir Osmangazi University, Eskisehir, Turkey \\ Email: draykutsahin@gmail.com
}

How to cite this paper: Sahin, A. and Ovali, C. (2020) Comparison of Coronary Bypass Grafting Surgery with Carotid Endarterectomy and Coronary Bypass Grafting Surgery. World Journal of Cardiovascular Surgery, 10, 11-17.

https://doi.org/10.4236/wjcs.2020.101002

Received: December 23, 2019

Accepted: January 14, 2020

Published: January 17, 2020

Copyright ( 2020 by author(s) and Scientific Research Publishing Inc. This work is licensed under the Creative Commons Attribution International License (CC BY 4.0).

http://creativecommons.org/licenses/by/4.0/

\begin{abstract}
Introduction: Treatment of combined coronary artery surgery (CABG) and severe carotid artery stenosis is still controversial. The decision of surgical priority can change according to the severity of the coronary artery disease or carotid artery disease at staged surgery. The aim of the study is to compare the outcomes of simultaneous surgery (CEA + CABG) and CABG alone at our department. Materials and Methods: We retrospectively reviewed the CABG and CEA + CABG patients which were performed between 2010 and 2015. If the patients had simultaneous another operation, they were excluded from the study. A total of 294 patients (252 CABG patients and 42 combined surgery patients), were retrospectively examined. Results: Two patients in CABG group and two patients in CABG + CEA group developed stroke. There was no statistically significant difference between the two groups in terms of early stroke rate $(p>0.05)$. One patient in CEA + CABG group and three patients in CABG group died. The average carotid clamp time was 19.93 \pm 5.06 minutes. Aortic clamp times were $42.89 \pm 6.38$ minutes in CABG and $42.81 \pm 5.70$ minutes in CEA + CABG patients. Results of the two groups were similar. Conclusion: Combined CEA and CABG can be performed successfully and safely in patients.
\end{abstract}

\section{Keywords}

Coronary Artery Surgery, Carotid Endarterectomy, Combined Surgery

\section{Introduction}

Being between $5 \%$ and $14 \%$, the incidence of combined coronary artery disease $(\mathrm{CoAD})$ and severe carotid artery disease (CaAD) is high. Treatment of the combination of the two diseases is still controversial [1]. Stroke is still an impor- 
tant complication of coronary artery bypass grafting (CABG). The benefit of carotid endarterectomy (CEA) over medical therapy in both symptomatic and asymptomatic patients has been established in randomized trials [2]. If the patients have left main coronary artery (LMCA) disease, proximal left anterior descending artery (LAD) disease or severe three-vessel CoAD, performing carotid endarterectomy (CEA) as the first line treatment has high risk [3]. Also, CoAD (LMCA and LAD lesions) presents high frequency (5\% - 14\%) with atherosclerosis of carotid arteries. Patients with LMCA and proximal LAD lesions should undergo carotid Doppler ultrasonography [1]. The patients with a concomitant $\mathrm{CoAD}$ and $\mathrm{CaAD}$ can be operated through staged approach or combined approach.

Surgeon can perform first carotid endarterectomy or CABG at staged approach. The decision of surgical priority can be changed according to the severity of the coronary artery disease or carotid artery disease. Some previous studies recommended staged operation based on that the simultaneous surgery has higher risk than staged surgery [4] [5] [6]. The aim of the study is to compare the outcomes of simultaneous surgery (CEA + CABG) and CABG alone at our department.

\section{Materials and Methods}

We retrospectively reviewed the CABG and CEA + CABG patients which were performed between 2010 and 2015. Patients historical health records were investigated for data. Preoperative risk factors, operative technique, perioperative morbidity, mortality, early and midterm results were evaluated. A total of 294 patients were included in the study. There were 252 patients in group 1 (CABG) and 42 patients in group $2(\mathrm{CEA}+\mathrm{CABG})$. The patients who received simultaneous other operation were excluded from study. CABG patients were evaluated with carotid Doppler ultrasonography. All surgeries were performed under general anesthesia. Firstly, CEA was performed in group 2. CEA was performed with classical approach using a patch. Before the carotid arteries were clamped 5000 IU heparin was administered intravenously. The dose of heparin was completed to $300 \mathrm{IU} / \mathrm{kg}$ after CEA, graft harvesting and sternotomy. Aorto-unicaval (two-staged) cannulation was performed in both groups. All CABG's were performed under cardiopulmonary bypass (CPB). Anastomoses were made with polypropylene sutures. While heparin was fully reversed in group 1. it was partially $(80 \%)$ reversed in group 2 because of the surgery of the CEA. After the operation patients were transferred to intensive care unit (ICU). CEA patients were monitored least one day in the ICU. Also, CABG + CEA patients were monitored at least two days in the ICU. If the patients didn't have any complication and the patent's hemodynamic parameters were normal, they were transferred to the ward.

If the patients had any complication, they investigated by other departments. Stroke patients were evaluated by neurology department with computerized to- 
mography (CT), magnetic resonance (MR) etc. Management of these patients was organized with neurologists. Early stroke and other complications were followed for 30 days.

PSPP version 1.2.0 software (Free Software Foundation Inc., Boston, MA, USA) was used for statistical analysis. The continuous variables were not normally distributed, so they were presented as mean with standard deviation. The categorical variables were presented as frequency and percentage rate. While continuous variables between two groups were compared with T-test, the categorical variables were compared with Chi-square test or Fischer's exact test with continuity correction. A p-value of $<0.05$ was considered statistically significant. Sample sizes were determined with G'Power analyses program; alpha value was 0.05 and power value was $80 \% G^{*}$ Power version 3.1.9.4 software (Heinrich-Heine-Universität Düsseldorf, Düsseldorf, Germany). Significant p-value was set to $<0.05$.

This study was approved by Eskisehir Osmangazi University Ethic Committee (8055871/G-47).

\section{Results}

The mean age of patients was $63.41 \pm 5.64$ ingroup 1 and $65.48 \pm 4.608$ ingroup 2. The rate of male gender was $58.3 \%$ in group 1 and $50 \%$ in group 2 . Smoking rates were also similar between the groups. Diabetes mellitus (DM) rates were $18.3 \%$ in group 1 and $33.3 \%$ in group 2 . The rate of DM was higher in group 2. $(\mathrm{p}<0.05)$ There was no statistical difference between the two groups in terms of the rate of smoking, hypertension, hyperlipidemia, peripheral artery disease and medical histories. There was 9.5\% bilateral carotid occlusion in group 2 (Table 1).

Carotid artery clamp-time was $19.93 \pm 5.067$ minutes in group 2. Aortic clamp times were $42.89 \pm 6.384$ minutes in group 1 and $42.81 \pm 5.701 \mathrm{~min}$ in group 2 . Mean operation-times were $203.31 \pm 17.084$ minutes in group 1 and $238.17 \pm$ 16.056 minutes in group 2 . There was a statistically significant difference in regards to operation-times which was due to the CEA surgery in group 2 ( $\mathrm{p}<$ 0.05). Postoperative stroke was detected $2(0.4 \%)$ patients in group 1 and 2 (4.8\%) patients in group 2. There was no significant difference between the two groups in regard to early stroke rate $(\mathrm{p}>0.05)$. The mean length of ICU-stay was $2.1 \pm 0.42$ days in group 1 and $2.1 \pm 2.2$ days in group 2 . The mean length of hospital-stay was $6.96 \pm 0.57$ days in group 1 and $6.08 \pm 0.67$ days in group 2 . The mean value of mediastinal bleeding was $497.56 \pm 63.84 \mathrm{ml}$ in group 1 and $648.81 \pm 155.82 \mathrm{ml}$ in group 2 . Bleeding was statistically higher in group 2 . There were $3(1.2 \%)$ mortality in group 1 and $1(2.4 \%)$ mortality in group 2 . Operative and postoperative data were revealed in Table 2. Patients were followed 30 days for early term results and one year for midterm results.

Mediastinal bleeding and operation time were statistically higher in group 2 . But there wasn't statistical difference about other perioperative and postoperative outcomes at both groups. 
Table 1. Comparison of demographic and clinical data.

\begin{tabular}{cccc}
\hline Variable & $\begin{array}{c}\text { Group 1 (n: 252) } \\
\text { n (\%) }\end{array}$ & $\begin{array}{c}\text { Group 2 (n: 42) } \\
\text { n (\%) }\end{array}$ & p-value \\
\hline Age (years) & $63.41 \pm 5.640$ & $65.48 \pm 4.608$ & $0.025(\mathrm{a})$ \\
Gender (Male) & $147(58.3)$ & $21(50.0)$ & $0.312(\mathrm{~b})$ \\
Smoke & $101(48.8)$ & $25(44.6)$ & $0.299(\mathrm{~b})$ \\
Diabetes mellitus & $46(18.3)$ & $14(33.3)$ & $0.025(\mathrm{~b})$ \\
Arterial Hypertension & $67(26.6)$ & $16(38.1)$ & $0.125(\mathrm{~b})$ \\
Bilateral Carotid Stenosis & & $4(9.5)$ & \\
PAD & $17(6.7)$ & $4(9.5)$ & 0.746 (c) \\
Medical History & $9.1(23)$ & $14.3(6)$ & 0.299 (b) \\
Hyperlipidemia & $47(18.7)$ & $16(38.1)$ & 0.004 (b) \\
MI & $85(33.7)$ & $15(35.7)$ & $0.189(\mathrm{~b})$ \\
\hline
\end{tabular}

PAD: Peripheral Arterial Disease, MI: Myocardial Infarction. ${ }^{a}$ Mann Whitney U test, ${ }^{b}$ Pearson Chi-Square, 'Fischer exact test (continuity correction).

Table 2. Clinical outcomes.

\begin{tabular}{cccc}
\hline & $\begin{array}{c}\text { Group 1 (n: 252) } \\
\text { n (\%) }\end{array}$ & $\begin{array}{c}\text { Group 2 (n: 42) } \\
\text { n (\%) }\end{array}$ & p-value \\
\hline Carotid X clamp (min) & - & $19.93 \pm 5.06$ & \\
Aortic X clamp (min) & $42.89 \pm 6.38$ & $42.81 \pm 5.70$ & $0.935(\mathrm{a})$ \\
Operation time (min) & $203.31 \pm 17.08$ & $238.17 \pm 16.05$ & $<0.001$ (a) \\
Postopetaive CVE & $2(0.8)$ & $2(4.8)$ & $0.182(\mathrm{~b})$ \\
Stroke sequel & $1(0.4)$ & $1(2.4)$ & 0.185 (b) \\
ICU time (day) & $2.1 \pm 0.42$ & $2.1 \pm 2.2$ & 0.780 (a) \\
Postoperative Stay (day) & $6.96 \pm 0.57$ & $6.08 \pm 0.67$ & 0.285 (a) \\
Bleeding (ml) & $497 \pm 63.8$ & $648 \pm 155.8$ & $<0.001$ (a) \\
Mortality & $3(1.2)$ & $1(2.4)$ & 1.000 (b) \\
\hline
\end{tabular}

X Clamp: Cross clamp, CVE: Cerebrovascular Event, ICU: Intensive care unit. ${ }^{a}$ Mann Whitney U test,

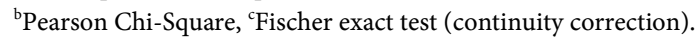

\section{Discussion}

The role of carotid artery stenosis in cerebrovascular events is at least $20 \%$. Carotid endarterectomy is the golden-standard treatment modality for severe carotid artery stenosis [7]. Stroke is an important complication of CABG [2]. Many articles pointed out the high risk of combined CEA and CABG approach [2] [3] [4]. Performing CABG primarily as the initial step in combined surgery could create high risk for stroke. On the other hand, performing CEA initially without CABG could have a high risk myocardial infarction [2] [5]. In which order these operations should be performed is still controversial. Many surgeons prefer CABG at first step, because of the myocardial infarction risk. If first step was CABG, there was stroke risk. CABG patients should be evaluated with carotid 
Doppler ultrasonography before operation [8].

Borger et al. evaluated a metanalysis of 16 publications. There were 844 combined and 920 staged operations. They show that the stroke and death rates in combined group were higher in two studies in these metanalyses. They stated that they needed more randomized and prospective studies for certain risks and results. They calculated 1500 patients needed for this prospective study [1]. In this study, there were $2(0.4 \%)$ strokes in group 1 and $2(4.8 \%)$ strokes in group 2. It seems that stroke ratio is higher in group 2 but no statistical difference was detected $(p>0.05)$. There was no severe carotid stenosis in CABG group. This is the difference of our study than the others. We think that this will reveal the better results. Group 1 is a valuable control group. Borger et al. revealed some publications showing that there was no statistical difference between combined and staged surgery [1].

$\mathrm{CPB}$ and carotid cross-clamp times were important determinants of perioperative stroke in CABG patients [1] [9] [10]. Mean carotid cross clamp time was $19.93 \pm 5.06$ minutes in group 2 in the current study. Aortic cross clamp time was $42.89 \pm 6.38$ minutes in group 1 and $42.81 \pm 5.70$ minutes in group 2 . Stroke rates could be similar between the two groups because of the similar aortic clamp times. Diagostino et al. showed that if aortic cross-clamp and CPB durations are high, the risk of stroke increases [10]. This result supports our study. However, in our study, the aortic cross-clamp time of one stroke patient was 33 minutes in group 1. Atrial fibrillation appeared in this patient at third postoperative day and right hemiparesis was revealed. There was no sequel after one month. One of the stroke patients in group 2 had aphasia in the ICU follow-up duration, but he fully recovered after one day. This patient's aortic cross-clamp time was 45 minutes, and carotid cross-clamp times were 26 minutes. Also, his total operation time was 248 minutes. There was one patient with right hemiparesis in group 1 and one patient with left hemiplegia in group 2 after six months. Total operation time was $203.31 \pm 17.08$ minutes in group 1 and $238.17 \pm 16.05$ minutes in group 2 . Total operation time was statistically higher in group 2 ( $\mathrm{p}<$ 0.05). There was no difference in stroke rate despite this statistical difference of operation times.

Total bleeding was higher in group $2(\mathrm{p}<0.05)$ The bleeding amounts were $497 \pm 63.8 \mathrm{ml}$ in group 1 and $648 \pm 155.8 \mathrm{ml}$ in group 2 . We think that this difference stemmed from the anticoagulation strategy. Heparin was partially reversed with protamine in CEA + CABG group, and $300 \mathrm{IU} /$ hour heparin infusion was started in the ICU after two hours of the operation. One patient underwent reoperation because of mediastinal bleeding in group 2. Newhall et al.'s metanalyses shown that partially reversed heparin causes more bleeding. On the other hand, full reversed heparin causes more reoperations, stroke and death [11]. Partial reversed heparin strategy was chosen to avoid serious complications in our department.

A three approach comparison study of Shishehbor et al. showed that the risk of myocardial infarction in staged operations was higher. Although the stroke 
rate was numerically higher than the others, they could not detect any statistical difference [12]. Gopaldas et al. compared two groups (Combined and staged surgery), and they stated that there was no difference between two groups in terms of mortality, stroke and inter-stage risks. However, the hospital charge of staged group was higher than combined group [13]. Yapici et al.'s study showed there was one major stroke in combined surgery and 3 deaths. They think it was an acceptable complication rate of combined surgery [14]. Kaul et al. didn't find statistical difference combined and staged group about mortality. They were using combined surgery routinely [8]. Also, our study showed similar stroke and death rates between the two groups. The duration of hospital stay and ICU stay between the groups were similar. This can indicate that combined surgery $(\mathrm{CABG}+\mathrm{CEA})$ is a safe method. CEA timing is important. Symptomatic and asymptomatic patients evaluated many times at big series and metanalyses [9] [13]. If there was CoAD with CaAD, CEA timing is more important. This study could guide to the timing of CEA at CaAD patients.

\section{Conclusion}

Combined CEA and CABG can be performed successfully and safely in patients. Also, combined surgery has some advantages like shorter hospital stay, acceptable early mortality and morbidity rates.

\section{Limitations}

This study has well-known retrospective design limitations. Also staged surgery was not investigated. But aim of the study was investigating safety of combined surgery. One of other limitation is number of combined surgery patients low. Power analyses were shown adequate patients at groups. Prospective and larger series could show better results.

\section{Conflicts of Interest}

The authors declare no conflicts of interest regarding the publication of this paper.

\section{References}

[1] Borger, M.A., Fremes, S.E., Weisel, R.D., et al. (1999) Coronary Bypass and Carotid Endarterectomy: Does a Combined Approach Increase Risk? A Meta-Analysis. The Annals of Thoracic Surgery, 68, 14-20. https://doi.org/10.1016/S0003-4975(99)00474-9

[2] Tarakji, K.G., Sabik, J.F., Bhudia, S.K., Batizy, L.H. and Blackstone, E.H. (2011) Temporal Onset, Risk Factors, and Outcomes Associated with Stroke after Coronary Artery Bypass Grafting. JAMA, 305, 381-390. https://doi.org/10.1001/jama.2011.37

[3] Cierie, E., De Rango, P., Maccaroni, M.R., Spaccatani, A. and Cao, P. (2008) Is Hemodynamic Depression during Carotid Stenting a Predictor of Periprocedural Complications? European Journal of Vascular and Endovascular Surgery, 35, 399-404.

[4] Hertzer, N.R., Loop, F.D., Taylor, P.C. and Beven, E.G. (1978) Staged and Com- 
bined Surgical Approach to Simultaneous Carotid and Coronary Vascular Disease. Surgery, 84, 803-811.

[5] Schwartz, R.L., Garrett, J.R., Karp, R.B. and Kouchoukos, N.T. (1982) Simultaneous Myocardial Revascularization and Carotid Endarterectomy. Circulation, 66, 97-101.

[6] Peric, M., Huskic, R., Nezic, D., et al. (1998) Combined Carotid and Coronary Artery Surgery: What Have We Learned after 15 Years? Cardiovascular Surgery, 6, 156-165. https://doi.org/10.1016/S0967-2109(97)00145-2

[7] Fox, A.J., Eliasziw, M., Rothwell, P.M. et al. (2005) Identification, Prognosis, and Management of Patients with Carotid Artery Near Occlusion. American Journal of Neuroradiology, 26, 2086-2094.

[8] Kaul, T.K., Fields, B.L., Riggins, L.S., Wyatt, D.A. and Jones, C.R. (2000) Coexistent Coronary and Cerebrovascular Disease: Results of Simultaneous Surgical Management in Specific Patient Groups. Cardiovascular Surgery, 8, 355-365. https://doi.org/10.1016/S0967-2109(00)00027-2

[9] Obied, H., Miari, A., Alreshidan, M., Alghofaili, F., Ibrahim, M., Albaradai, A. and Koudieh, M. (2014) Incidence \& Risk Factors Associated with Carotid Disease in Patients Undergoing Coronary Artery Bypass Grafting Surgery. Open Journal of Thoracic Surgery, 4, 17-20. https://doi.org/10.4236/ojts.2014.42005

[10] D’Agostino, R.S., Svenssson, L.G., Neuman, D.J., et al. (1996) Screening Carotid Ultrasonography and Risk Factors for Stroke in Coronary Artery Surgery Patients. The Annals of Thoracic Surgery, 62, 1714-1723. https://doi.org/10.1016/S0003-4975(96)00885-5

[11] Newhall, K.A., Saunders, E.C., Larson, R.J., Stone, D.H. and Goodney, P.P. (2016) Use of Protamine for Anticoagulation during Carotid Endarterectomy: A Meta-Analysis. JAMA Surgery, 151, 247-255. https://doi.org/10.1001/jamasurg.2015.3592

[12] Shishehbor, M.H., Venkatachalam, S., Sun, Z., et al. (2013) A Direct Comparison of Early and Late Outcomes with Three Approaches to Carotid Revascularization and Open Heart Surgery. Journal of the American College of Cardiology, 62, 1948-1956. https://doi.org/10.1016/j.jacc.2013.03.094

[13] Gopaldas, R.R., Chu, D., Dao, T.K., et al. (2011) Staged versus Synchronous Carotid Endarterectomy and Coronary Artery Bypass Grafting: Analysis of 10-Year Nationwide Outcomes. The Annals of Thoracic Surgery, 91, 1323-1329. https://doi.org/10.1016/j.athoracsur.2011.02.053

[14] Yapici, F., Gürer, O., Enç, Y., Cinar, B., Güney, M.R., Yapici, N., Bilgen, F. and Ozler, A. (2002) Combined Surgery for Coronary and Carotid Artery Disease: Management and Results. Journal of Turkish Thoracic and Cardiovascular Surgery, 10, 229-234. 